
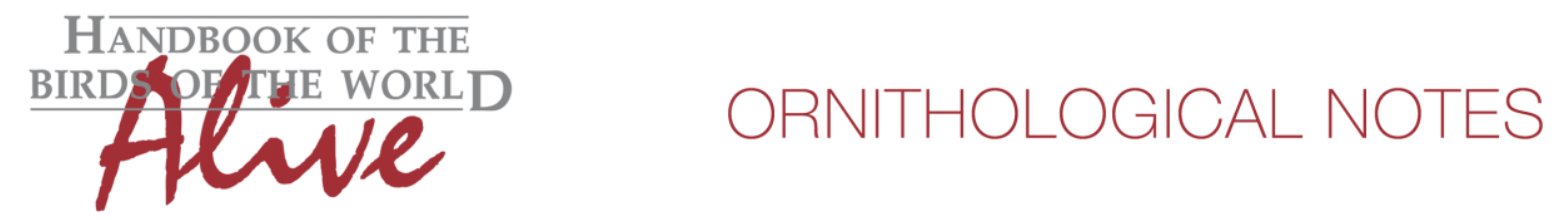

\title{
Notes on the vocalizations of Plain Martin (Riparia paludicola)
}

Peter Boesman

In the following we briefly analyze and compare voice of the different races of Plain Martin (Riparia paludicola). We also try to quantify the extent of any vocal differences using the criteria proposed by Tobias et al. (2010), as a support for taxonomic review. We have made use of sound recordings available on-line from Xeno Canto (XC), Macaulay Library (ML), Avian Vocalizations Center (AVoCet) and The Internet Bird Collection (IBC).

From a quick look at existing recordings of this species complex, it would seem that vocabulary is quite varied, but there are very few recordings available, distributed over the several races. An overview, illustrated with sonograms:

mauritanica (W Morocco), minor (locally from Senegambia E to Sudan and N Ethiopia), ducis (E DRCongo, Uganda and W \& C Kenya S to Burundi and N \& C Tanzania) and newtoni (SE Nigeria and adjacent $W$ Cameroon): No recordings available.

schoensis (Ethiopian Highlands)

* buzzy notes:

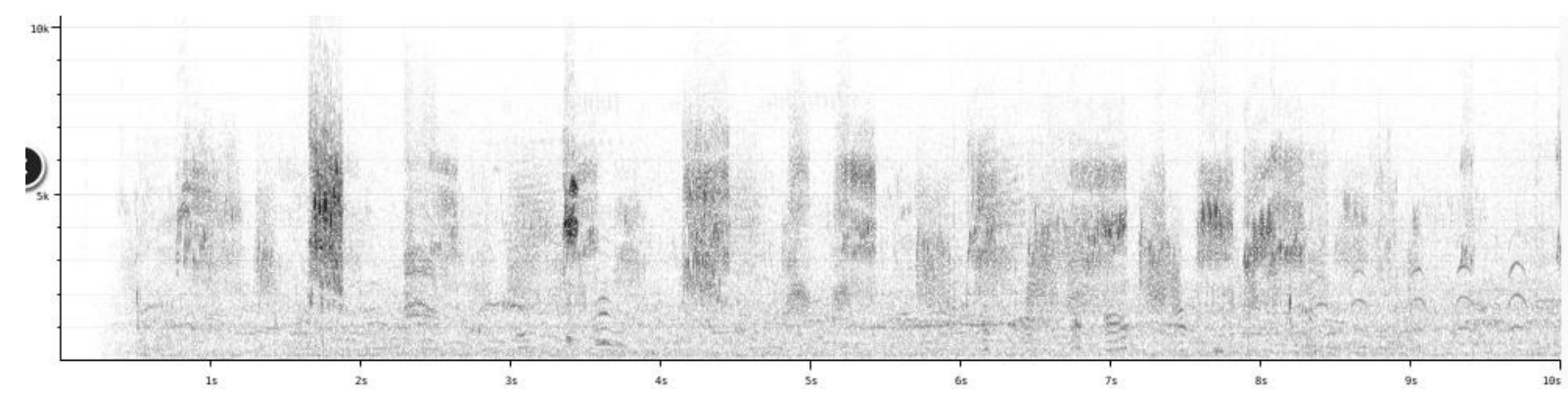

* clear, slightly nasal notes:

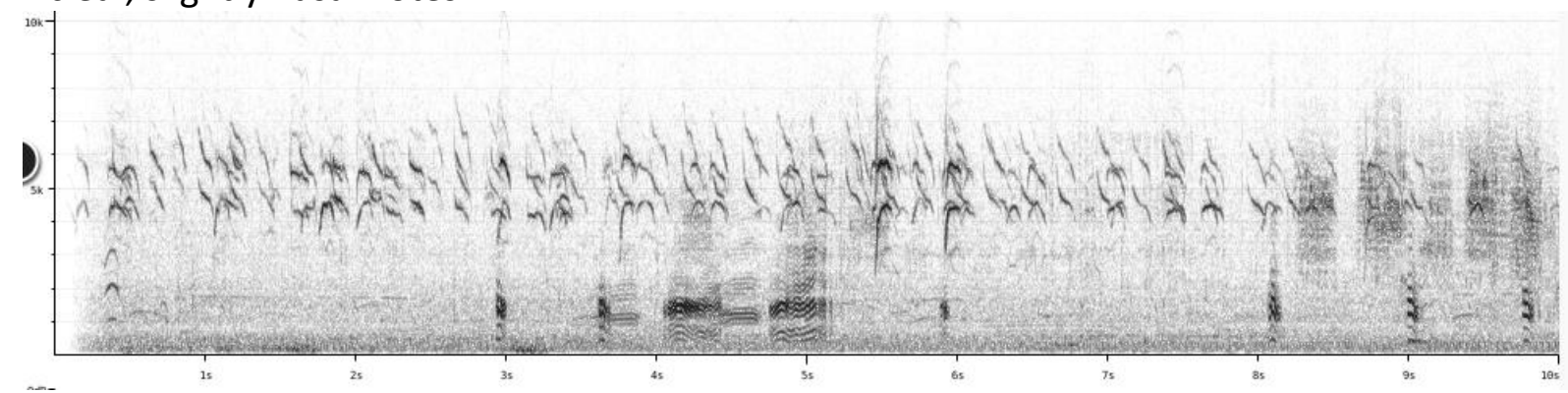




\section{HANDBOOK OF THE

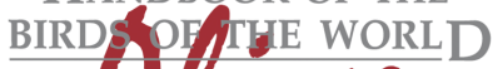 \\ Alue}

\section{ORNITHOLOGICAL NOTES}

paludicola (W \& SW Angola, Zambia, S Tanzania and Malawi S to South Africa)

* short stuttered series

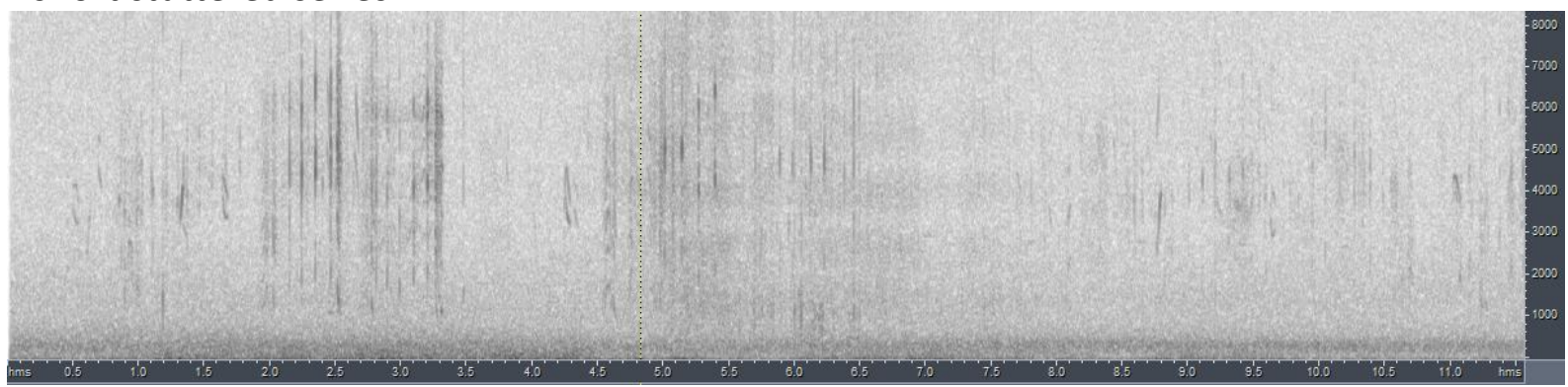

* buzzy to raspy notes

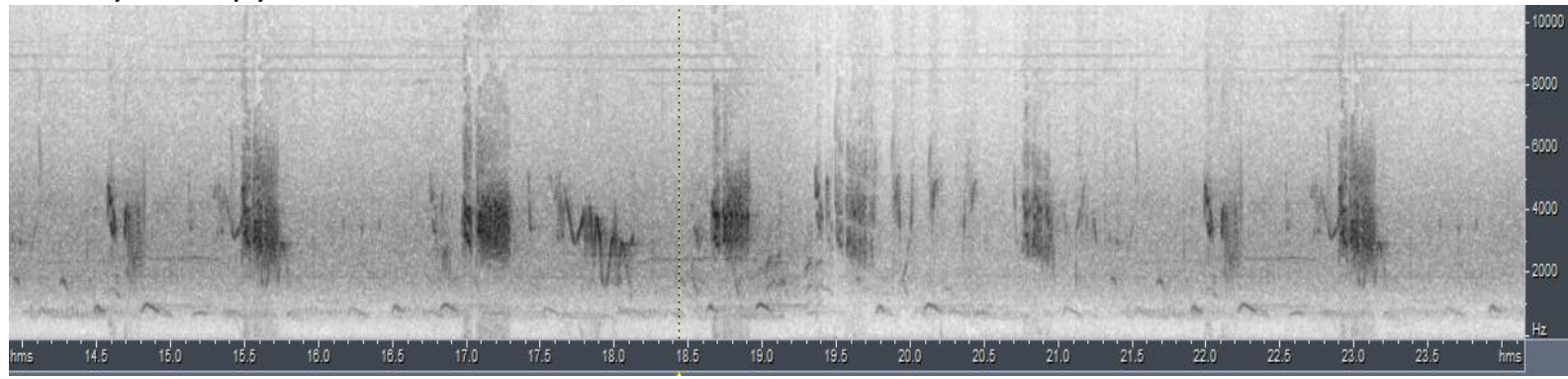

cowani (E Madagascar)

Vocalizations seemingly very different $(n=5)$ :

* a nasal stuttered phrase of short overslurred notes, like a short whinny

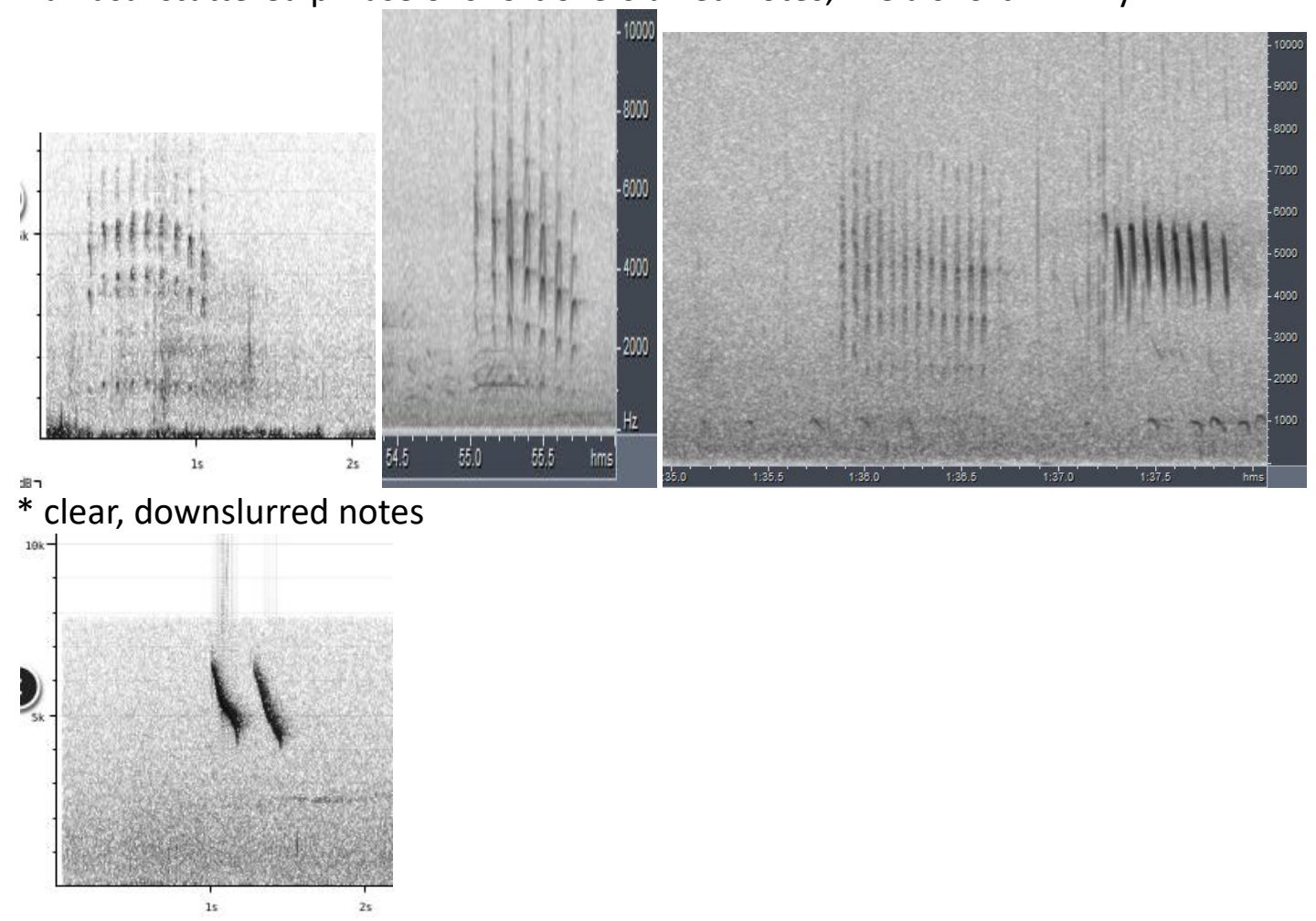




\section{HANDBOOK OF THE \\ BIRDS PF,THE WORLD Aluve}

\section{ORNITHOLOGICAL NOTES}

chinensis (S Tadjikistan, N Afghanistan, Pakistan and N India E to Myanmar, S China (S Yunnan) and Indochina, also Taiwan)

* short chirps $(n=1)$

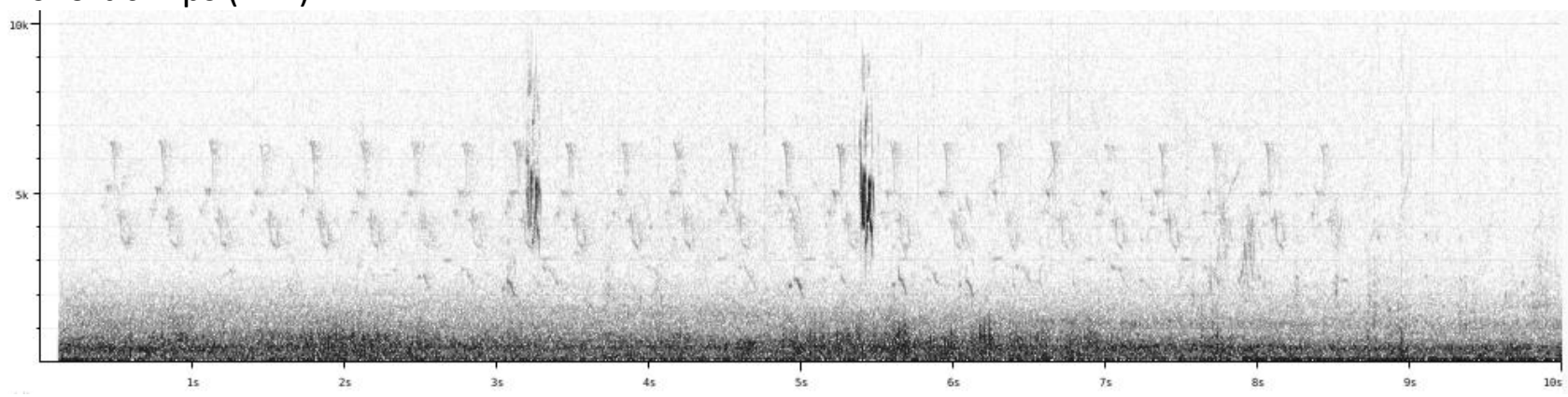

* short rattles

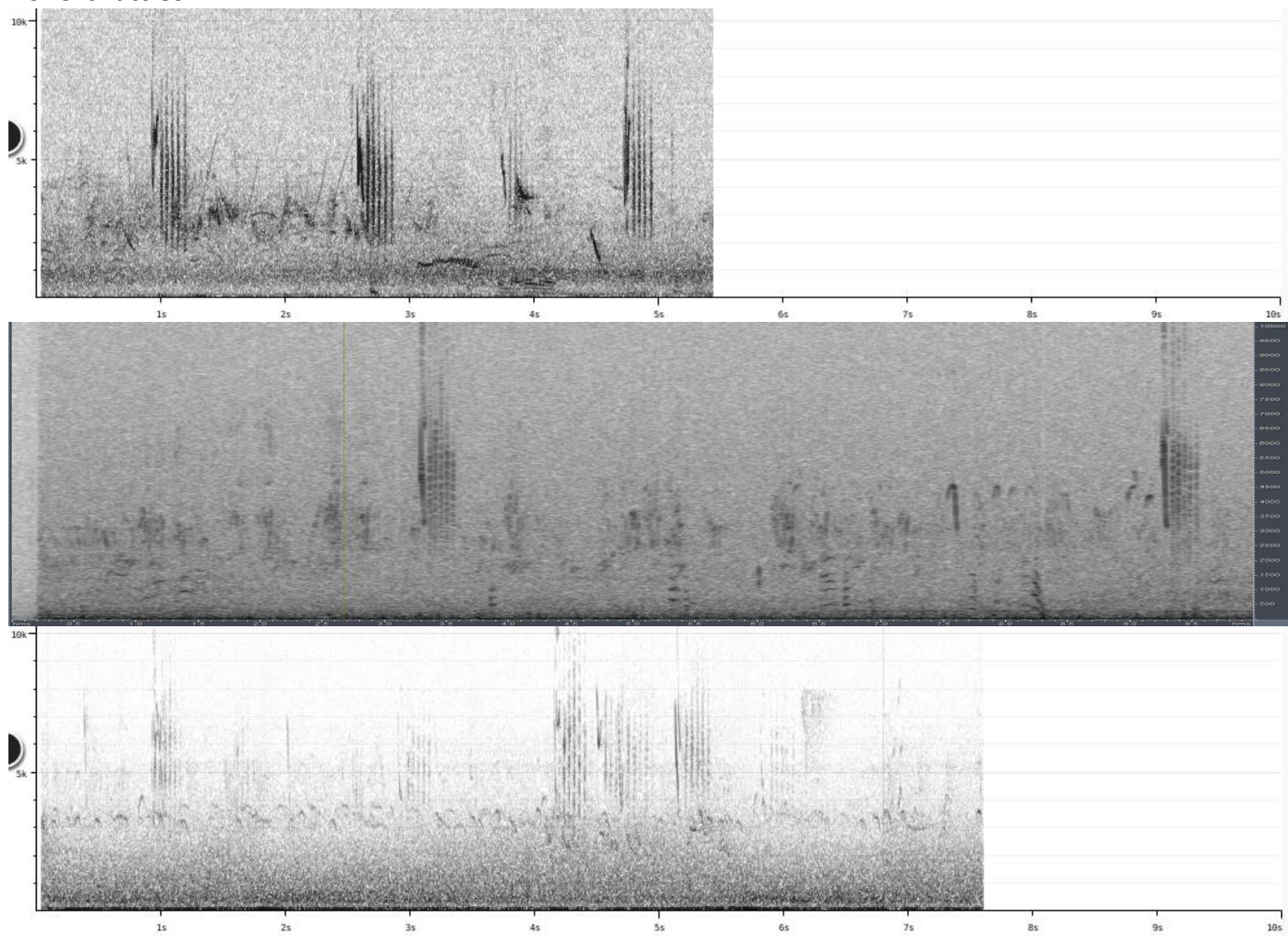

Myanmar??

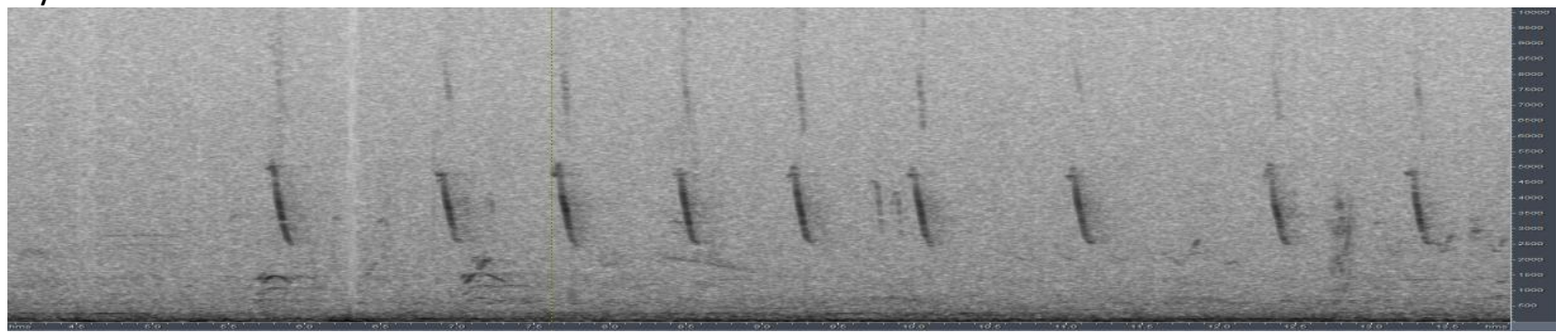

tantilla (N Philippines (Luzon)): No recordings available. 

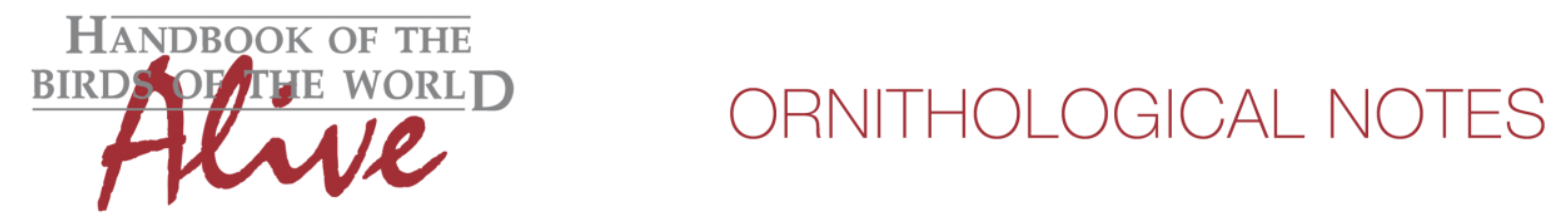

This is obviously a very incomplete picture of the vocalizations of all races.

Most striking is the different voice of race cowani from Madagascar, which seems to consistently utter very different vocalizations compared to all other races (it is unclear which are equivalent homologous vocalizations in other races, we can therefore only tentatively score the short whinny based on pace and number of notes (allow 3 ) and the clear downslurred notes based on note length (allow 2).

At least mainland African races schoensis and paludicola share buzzy notes, which seem to be lacking in Asian race chinensis: we have three near-identical recordings of chinensis of short rattles, which we haven't found in other races. Several cuts of chinensis with a multitude of calls (also of other birds, and it is far from clear which calls are from Plain Martin) do not have buzzy calls. These strengthen the idea that chinensis is vocally distinctive.

We have very few or no recordings of several of the African races. We are thus fully aware that it is a bit speculative to conclude that mainland African races have several calls, of which some are distinctly buzzy, while chinensis has no buzzy calls and among its calls a distinct short rattle. This vocal difference could be given tentatively a score of about 3 , but we need more recordings of all races to confirm this statement.

This note was finalized on 12th July 2016, using sound recordings available on-line at that moment. We would like to thank in particular the sound recordists who placed their recordings for this species on XC and ML: Peter Boesman, Fernand Deroussen, Albert Lastukhin, Linda Macaulay, Arnold Meijer, Rory Nefdt, Mike Nelson, Craig Robson, Lynette Rudman and Thomas Schulenberg.

\section{References}

Tobias, J.A., Seddon, N., Spottiswoode, C.N., Pilgrim, J.D., Fishpool, L.D.C. \& Collar, N.J. (2010). Quantitative criteria for species delimitation. Ibis 152(4): 724-746.

\section{Recommended citation}

Boesman, P. (2016). Notes on the vocalizations of Plain Martin (Riparia paludicola). HBW Alive Ornithological Note 412. In: Handbook of the Birds of the World Alive. Lynx Edicions, Barcelona. (retrieved from http://www.hbw.com/node/1253813 on 4 December 2016). 